\title{
SINGLE-WALLED CARBON NANOTUBES FOR HETEROJUNCTION SOLAR CELLS
}

\author{
Kehang Cui $^{1}$, Takaaki Chiba ${ }^{1}$, Shohei Chiashi ${ }^{1}$, Esko I. Kauppinen ${ }^{2}$, Shigeo Maruyama ${ }^{1 *}$ \\ ${ }^{1}$ Department of Mechanical Engineering, The University of Tokyo, Hongo 7-3-1, Bunkyo-ku, Tokyo 113- \\ 8656, Japan \\ ${ }^{2}$ Department of Applied Physics, Aalto University, Otakaari 1, 02150 Espoo, FI-20742, Finland
}

\begin{abstract}
Single-walled carbon nanotubes (SWNTs) with outstanding electronic, optical, mechanical and thermal properties are expected to be the most promising materials for next-generation energy as well as optical and electronic devices. However, the structure-controlled assembling of SWNTs to macroscale for various devices is still challenging. This study focused on the SWNT assemblies for improving the performance of SWNT-Si heterojunction solar cells. A water vapor breath figure method to build up SWNTs into a self-assembled microhoneycomb network for the applications of solar cells has been developed. The micro-honeycomb network consists of vertical aggregated SWNT walls and a buckypaper bottom (quasi two-dimensional random network). The pristine micro-honeycomb structured SWNT-Si heterojunction solar cell shows a record-high fill factor of $72 \%$ as well as a stable power conversion efficiency (PCE) of $6.04 \%$. The PCE increased to $10.02 \%$ in the dry state after the dilute nitric acid treatment. For comparison, the state-of-the-art randomly oriented SWNT films with high transparency and with low sheet resistance were also used for fabricating solar cells. The PCE and fill factor of the randomly oriented SWNT-Si solar cell are $10.12 \%$ and $61 \%$, respectively. In addition, the relationship between the equivalent series resistance and the fill factor was investigated through the diode equation modeling. This study demonstrates that the micro-honeycomb structure formed by the condensation and evaporation of the water vapor is beneficial for improving the performance of solar cell, especially in terms of the fill factor.
\end{abstract}

KEY WORDS: Nano / Micro, Solar energy, Carbon nanotubes

\section{INTRODUCTION}

Single-walled carbon nanotubes (SWNTs) are one-dimensional quantum wires [1] featured with outstanding electronic, optical, mechanical and thermal properties. Considered as one of the most promising materials for photovoltaic and photo-electrochemical cells, SWNTs have been exploited by all means, including photocurrent generation sites [2], photoelectrochemical reaction scaffolds [3] and electrodes [4]. However, the gap between the superior nanoscale properties of individual SWNTs and the less impressive performance of their micro/macroscale assemblies is hindering the realization of their full potential.

SWNT-Si solar cells with high power-conversion efficiency (PCE) $[5,6]$ have emergent technological impact owing to their high efficiency, structural simplicity as well as the simple, low-temperature and lowcost fabrication processes. Many efforts have been made to improve the PCE and the fill factor of SWNT-Si solar cells. These improvements were mainly realized by chemical modification of carbon nanotube films, which were on the other hand, usually unstable. Moreover, carefully designing the morphology of SWNTs provides an alternative to efficiently organize the charge generation, separation and transport at solar-cell interfaces, which is very critical for solar cells. Self-assembly is a simple and low-cost way for building

*Corresponding Author: maruyama@photon.t.u-tokyo.ac.jp 
nanomaterials and has been used for nanowires [7], nanopillars [8] and multiwalled carbon nanotubes [9]. However, the self-assembly of SWNTs is very difficult because of their very small diameters and superhydrophobicity.

In this research, we present a novel water vapor treatment process to build up the as-synthesized vertically aligned SWNTs (VA-SWNTs) into a self-assembled hierarchical micro-honeycomb network $(\mu-\mathrm{HN})$. The condensation and evaporation of the water vapor on the VA-SWNTs resulted in the self-assembly process of the SWNTs. The $\mu$-HN SWNT film and the state-of-the-art randomly oriented SWNT film were used for the SWNT-Si solar cells. The record-high fill factor of $72 \%$ was obtained for the pristine SWNT-Si solar cell using the $\mu$-HN SWNT film, while the very high PCE of $10.12 \%$ was achieved for that using the pristine randomly oriented SWNT film. The performances of all the fabricated solar cells in this study were stable in the ambient environment for up to six months, which was reported for the first time. Moreover, the diode equation model was used to fit the experimental results, aiming at extracting the series resistance and shunt resistance of the SWNT-Si solar cells. This study shows that the morphology of the SWNTs is really critical for the further improvement of the SWNT-Si solar cells.

\section{EXPERIMENTAL DETAILS}

2.1 Growth of Vertically-Aligned SWNTs Vertically-aligned SWNTs were grown on Co/Mo dip-coated $\mathrm{Si} / \mathrm{SiO}_{2}$ substrates using the alcohol catalytic CVD (ACCVD) process in our group [10]. The substrate loaded with $\mathrm{Co} / \mathrm{Mo}$ bimetallic nanoparticle catalysts was placed in a quartz tube surrounded by the electric furnace after the dip-coating process and heated under a flow of $300 \mathrm{sccm}$ of Ar containing $3 \% \mathrm{H}_{2}$ at $40 \mathrm{kPa}$ to $800{ }^{\circ} \mathrm{C}$ in $30 \mathrm{~min}$. The substrate was then annealed at $800{ }^{\circ} \mathrm{C}$ for $10 \mathrm{~min}$ before the ethanol feedstock (dehydrated, 99.5\%, Wako Chemical, Inc.) was introduced with a flow rate of $100 \mathrm{sccm}$ at $1.3 \mathrm{kPa}$. The growth process of VA-SWNTs can be monitored by the in situ laser absorption technique for quartz substrates. In this study, the length of the VA-SWNT films was controlled as $5 \mu \mathrm{m}$, as shown in the SEM images of Fig. 1a and Fig. 1b.

2.2 Growth of Random-Oriented SWNT The randomly oriented SWNT films with high purity were synthesized by the aerosol CVD method developed by NanoMaterial Group at Aalto University, Finland [11]. Ferrocene vapor was thermally decomposed to iron nanoparticles at the temperature of $880{ }^{\circ} \mathrm{C}$. The $\mathrm{CO}$ was flowed at $4 \mathrm{~L} / \mathrm{min}$ and decomposed on the above-mentioned iron nanoparticles where SWNTs growth occurred. By varying the temperature in the reactor, the diameter of SWNTs could be tuned to a certain extent. The as-synthesized SWNTs were collected by low-adhesion microporous filters at the downstream of the reactor. The transparency of the SWNT films can be varied by changing the collection time. The collected SWNT films can be transferred to arbitrary substrates through a dry transfer process [11]. The SEM image of the randomly oriented SWNT film is shown in Fig. 1c.
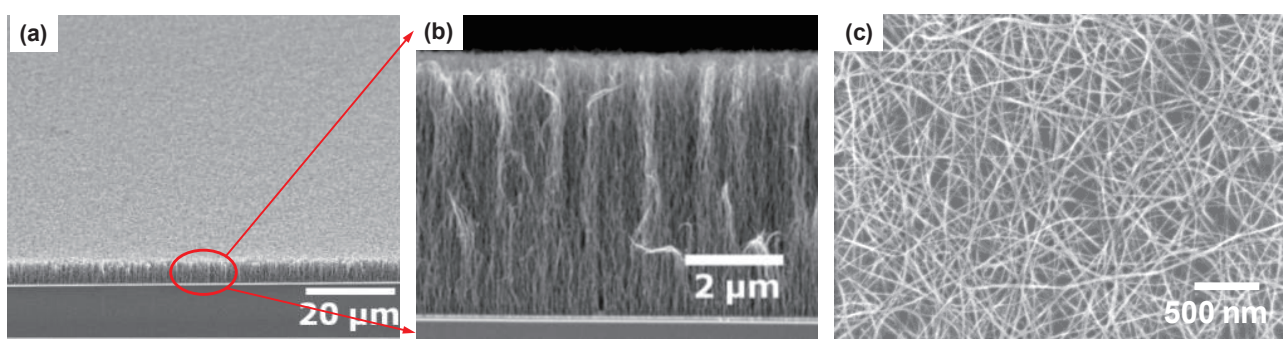

Fig. 1 (a) As-synthesized VA-SWNT with uniform surface. (b) Magnified SEM image of the thickness of the VA-SWNTs. (c) The SEM image of the randomly oriented SWNT film.

2.3 Breath Figure Method (Water Vapor Treatment) After ACCVD synthesis, the water vapor treatment includes two steps: (1) expose the VA-SWNT array to vapor from a hot water reservoir, and (2) turn the substrate over and dry the array in the ambient environment. The schematic of the water vapor treatment is given in Fig. 2a. The uniform VA-SWNT array (Fig. 2b) was aggregated into hexagonal frames 
after the first water vapor treatment. By repeating this treatment 20 to 30 times, the VA-SWNT array evolved into a $\mu-\mathrm{HN}$. The schematic of the $\mu-\mathrm{HN}$ is shown in Fig. 2c. The liquid-solid interaction induced by the condensation and subsequent evaporation of water is the building tool used to engineer the morphology of VA-SWNTs into a self-assembled $\mu-\mathrm{HN}$ [12]. The $\mu-\mathrm{HN}$ is a hierarchical hexagonal-shaped threedimensional network that consists of vertical SWNT walls and a randomly networked SWNT bottom. Each wall is a cross-linked high-density SWNT agglomeration (Fig. 2d) and the bottom of the honeycomb cell is a randomly oriented buckypaper (Fig. 2e), which is resulted from the collapse of SWNT alignment. The most energetically favorable outcome is a honeycomb network, because it would uniformly divide the region into cells having the minimal perimeter, i.e., allow the largest number of SWNTs to collapse.

(a)

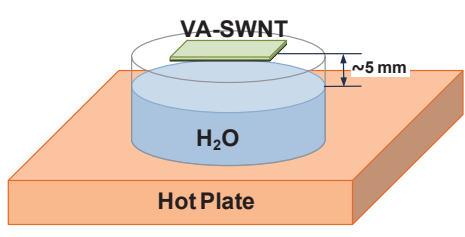

Water vapor treatment (b)

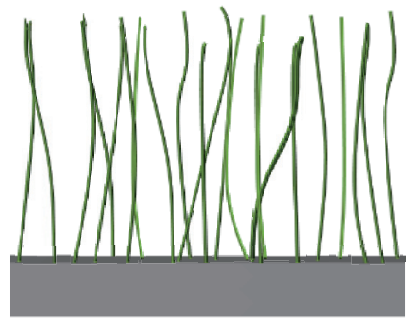

Before Treatment

(c)

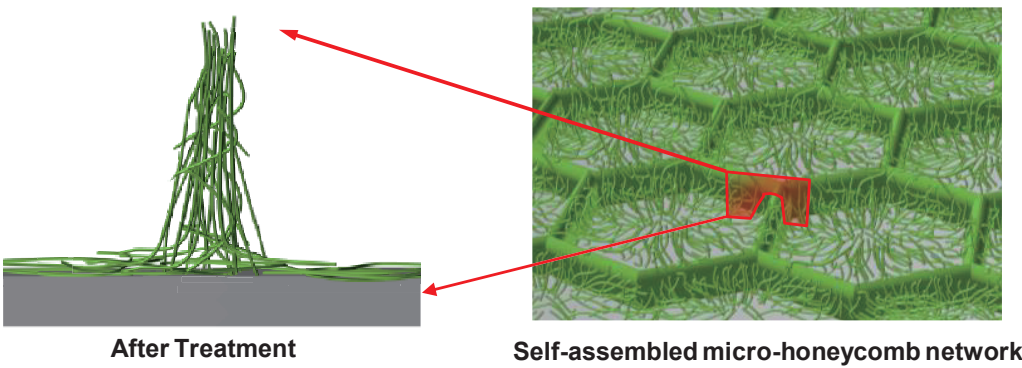

(d)
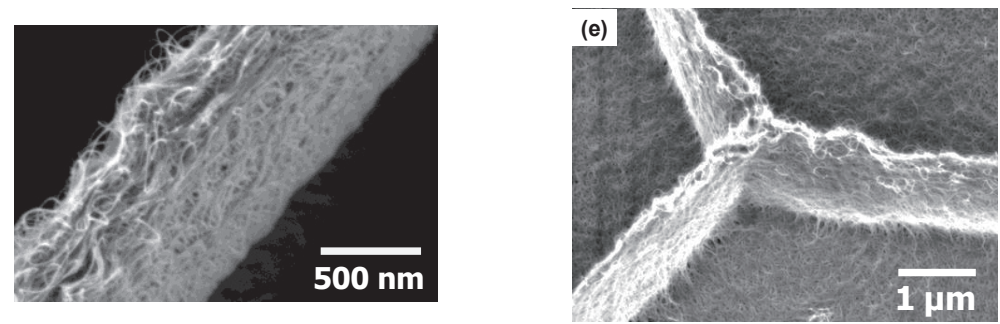

Fig. 2 (a) The schematic of the water vapor treatment. (b) The schematic of the as-synthesized uniform VASWNT array before water vapor treatment. (c) The schematic of the stable $\mu$-HN formed after $20 \sim 30$ iterations of the water vapor treatment. (d) The SEM image of a dense SWNT wall of an individual honeycomb cell. (e) The magnified image of the three-dimensional hierarchical $\mu-\mathrm{HN}$ with dense SWNT wall and randomly oriented bottom.

2.4 Solar Cell Fabrication Each SWNT-Si solar cell was formed by transferring the SWNT film onto a n-type Si substrate. The n-type Si (SUMCO Inc.) has a series resistance of approximately $10 \Omega / \mathrm{cm}$ with the dopants concentration $\sim 10^{15} \mathrm{~m}^{-3}$. Before the metal deposition, the n-type Si substrate was consequentially treated with RCA1, $5 \mathrm{M} \mathrm{NaOH}$ and RCA2 solution for the removal of oxide layer and impurity metals. A very thin oxide layer was formed with the thickness of $6 \AA \sim 7 \AA$, according to the Si $2 p$ spectrum measured by the X-ray photoelectron spectroscopy [13]. An array of $3 \mathrm{~mm} \times 3 \mathrm{~mm}$ sized physical masks was patterned on the top surface of the $\mathrm{Si}$ substrate before metal deposition. A 200-nm-thick $\mathrm{SiO}_{2}$ insulator layer and a 50nm-thick Pt electrode were subsequently RF-sputtered (ULVAC-RIKO, Inc.) on the top surface of the $\mathrm{Si}$ substrate. Ti with the thickness of $10 \mathrm{~nm}$ was selected as the back electrode for the lineup of the band 
structure. Fig. 3 shows the transfer process and the schematic of the fabricated SWNT-Si solar cell. The randomly-oriented SWNT films were transferred on the Si substrate by a dry-transfer process [11].

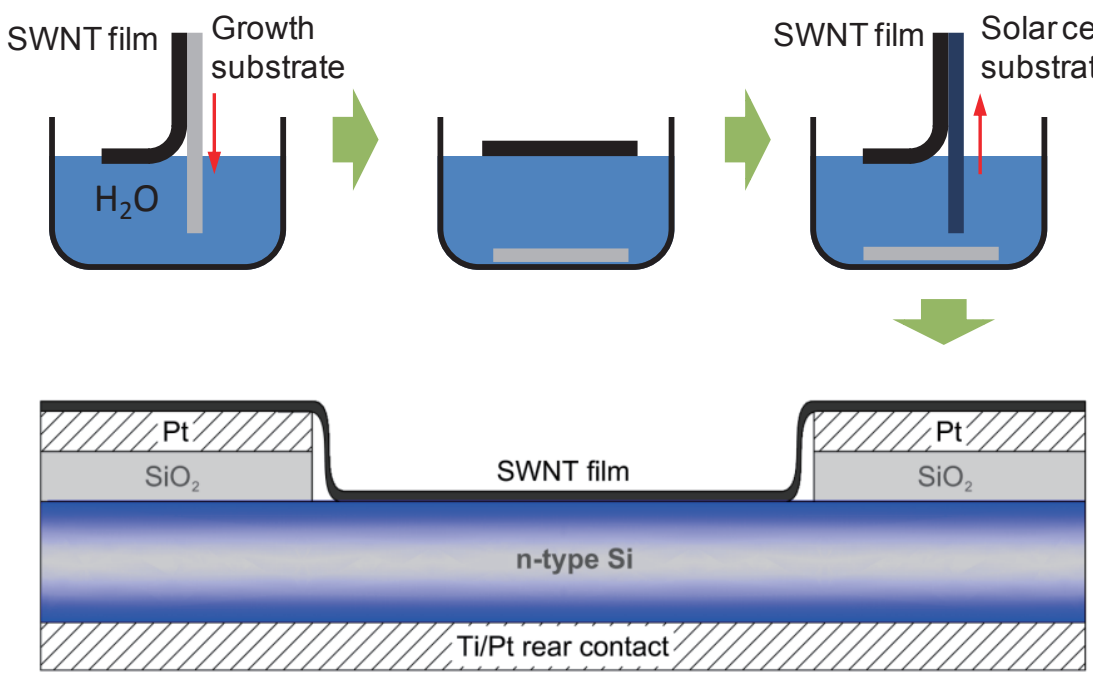

Fig. 3 Transfer process of the self-assembled SWNT films onto the Si substrate for the fabrication of SWNT-Si solar cells and schematic of the fabricated solar cell.

\section{RESULTS AND DISCUSSIONS}

3.1 Self-Assembly of SWNTs The formation of the $\mu$-HN is mainly determined by the two factors, i.e., water reservoir temperature and vapor exposure time. A $10 \mu \mathrm{L}$ water droplet was dropped onto the top surface of a VA-SWNT film at room temperature as the control group. As shown in Fig. 4a, the top surface of the VA-SWNT array is super-hydrophobic with very large contact angle. After evaporation of the water, the SWNTs aggregate into a highly condensed bulk and generated many $100-\mu \mathrm{m}$-scale gaps, as shown in Fig. $4 \mathrm{~b}$ and Fig. 4c, which is in agreement with the result reported [9]. The white part in Fig. 4(b) (or grey part in Fig. 4(c)) is the surface of the bare silicon, while the black part in Fig. 4(b) and Fig. 4(c) is the aggregated SWNTs. Similar phenomena were observed for an ethanol droplet at room temperature and a water droplet at $80{ }^{\circ} \mathrm{C}$. In the case of water vapor treatment, when the water reservoir temperature was $50{ }^{\circ} \mathrm{C}$, the length of the gaps decreased to $\sim 50 \mu \mathrm{m}$ and honeycomb cells started to form (Fig. 5a). The increase of the water reservoir temperature to $70{ }^{\circ} \mathrm{C}$ significantly reduced the size of the gaps to approximately $5 \mu \mathrm{m}$, and the size of honeycomb cells became more uniform (Fig. 5b). A well-formed $\mu$-HN was obtained when the water reservoir temperature reached $80{ }^{\circ} \mathrm{C}$ (Fig. 5c). The vapor exposure time for the structures shown in Fig. 5 was set as $5 \mathrm{~s}$ for all above-mentioned cases.
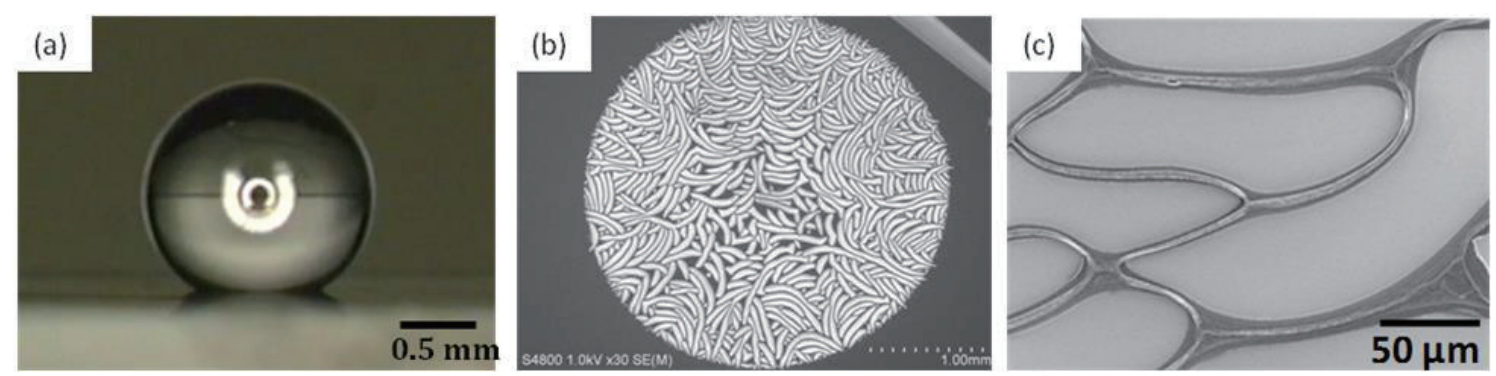

Fig. 4 (a) A water droplet on the superhydrophobic surface of a VA-SWNT array. (b) The pattern obtained by applying a $10 \mu \mathrm{L}$ water droplet to the surface at room temperature. (c) The magnified image of the densed SWNT walls with $100-\mu \mathrm{m}$-scale gaps. 
The effect of vapor exposure time on the morphology was also investigated using a constant water reservoir temperature of $80{ }^{\circ} \mathrm{C}$. Extending the exposure time from $2 \mathrm{~s}$ to $5 \mathrm{~s}$ resulted in an increase in microhoneycomb cell size from $\sim 2.5 \mu \mathrm{m}$ (Fig. 6a) to $\sim 12 \mu \mathrm{m}$ (Fig. 6b). When the exposure time was longer than $15 \mathrm{~s}$, most of the VA-SWNTs collapsed and the walls of the cells nearly disappeared, as shown in Fig. 6c. Compared with the direct immersion or direct wetting (water droplet), the water vapor treatment apears to be a more delicate and controllable method to assemble the VA-SWNTs. The optimal parameters of water vapor treatment for the formation of $\mu-\mathrm{HN}$ (Fig. 6b) are vapor from an $80{ }^{\circ} \mathrm{C}$ reservoir for $5 \mathrm{~s}$ with 30 iterations.
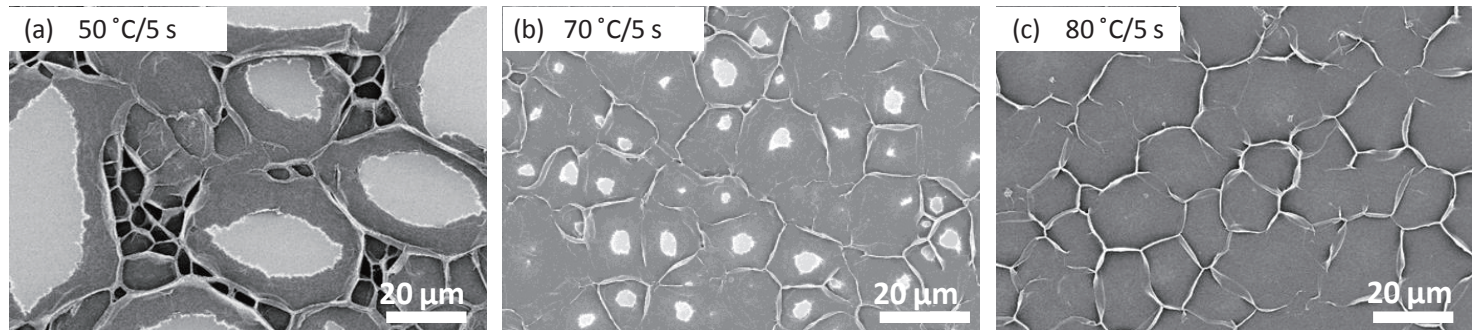

Fig. 5 Morphologies obtained by the exposure to (a) $50{ }^{\circ} \mathrm{C}$, (b) $70{ }^{\circ} \mathrm{C}$ and (c) $80{ }^{\circ} \mathrm{C}$ water reservoirs, respectively. The vapor exposure time for each vapor treatment step was $5 \mathrm{~s}$.
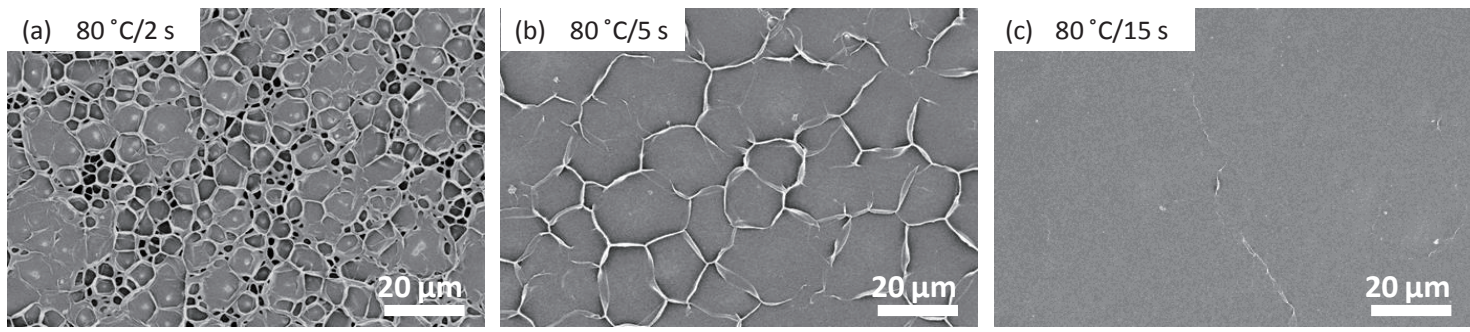

Fig. 6 Morphologies obtained with the vapor exposure durations of (a) $2 \mathrm{~s}$, (b) $5 \mathrm{~s}$ and (c) $15 \mathrm{~s}$ for each iteration, respectively. The reservoir temperature was set at $80^{\circ} \mathrm{C}$.

3.2 Solar Cell Performance Four kinds of SWNT films, i.e., the micro-honeycomb network $(\mu-\mathrm{HN}$, Fig. 6b), the collapsed honeycomb network (collapsed HN, Fig. 6c), the porous honeycomb network (porous HN, Fig. 5b) and the randomly oriented SWNT film (TCF90, Fig. 1c) are employed for fabricating SWNT-Si solar cells. Each SWNT film was transferred onto the top surface of the Si substrate after the removal of the $3 \mathrm{~mm} \times 3 \mathrm{~mm}$ physical masks. The SWNT-Si diode was formed after the transfer.

The current density-voltage $(J-V)$ characteristics of the SWNT-Si solar cells using the $\mu-\mathrm{HN}$, the collapsed $\mathrm{HN}$, the porous $\mathrm{HN}$ and the TCF90 films were measured under $100 \mathrm{~mW} / \mathrm{cm}^{2} \mathrm{AM} 1.5 \mathrm{G}$ illumination (PECL01, Peccell Technologies, Inc.) and dark conditions, as shown in Fig. 7a and Fig. 7b. From Fig. 7a, the SWNT-Si solar cell using the $\mu-\mathrm{HN}$ possessed better performances than those using the collapsed $\mathrm{HN}$ and porous HN. The PCE value of the $\mu-\mathrm{HN}$ SWNT-Si heterojunction solar cell was $5.91 \%$ measured immediately after the fabrication and gradually increased to $6.04 \%$ after three weeks in ambient conditions. Its PCE boosted to $10.02 \%$ after $2.4 \mathrm{M}$ nitric acid doping, as shown in Fig. $7 \mathrm{~b}$. The nitric acid treatment will $p$-dope [14] the SWNT film. The obtained peak PCE value for the solar cell with the pristine TCF90 SWNT film was $10.12 \%$, which was comparable to the SWNT/Si solar cells doped with nitric acid and gold salt in previous literatures [5-6]. As shown in the Fig. 7, the $J_{s c}$ value of the solar cell sample with the TCF90 film was $30 \mathrm{~mA} / \mathrm{cm}^{2}$, which was the highest among the fabricated solar cells. The superiority of the TCF90 SWNT-Si solar cell over the previous results is attributed to the well-retained high crystallinity, long tube length of the randomly-oriented SWNTs [11] as well as the sound inter-SWNT and SWNT-Si contact. 
The fill factor (FF) determines the quality of a solar cell, which is one of the three criteria characterizing the solar cell performance along with short-circuit current $\left(J_{s c}\right)$ and open-circuit voltage $\left(V_{o c}\right)$. In this study, the FFs of the SWNT-Si solar cells using the pristine $\mu-\mathrm{HN}$, the collapsed HN, the porous HN and the TCF90 films were $72 \%, 70 \%, 68 \%$ and $61 \%$, respectively. The pristine $\mu$-HN SWNT-Si solar cell exhibited the highest and stable FF with an ideality factor of 1.71 over the 300 to $500 \mathrm{mV}$ bias range. To our knowledge, this ideality factor is the lowest reported so far. The highest FF of the pristine $\mu$-HN SWNT-Si solar cell demonstrated that the SWNT films with the three-dimensional $\mu-\mathrm{HN}$ could organize the charge separation, collection and transport in a more efficient way [12].
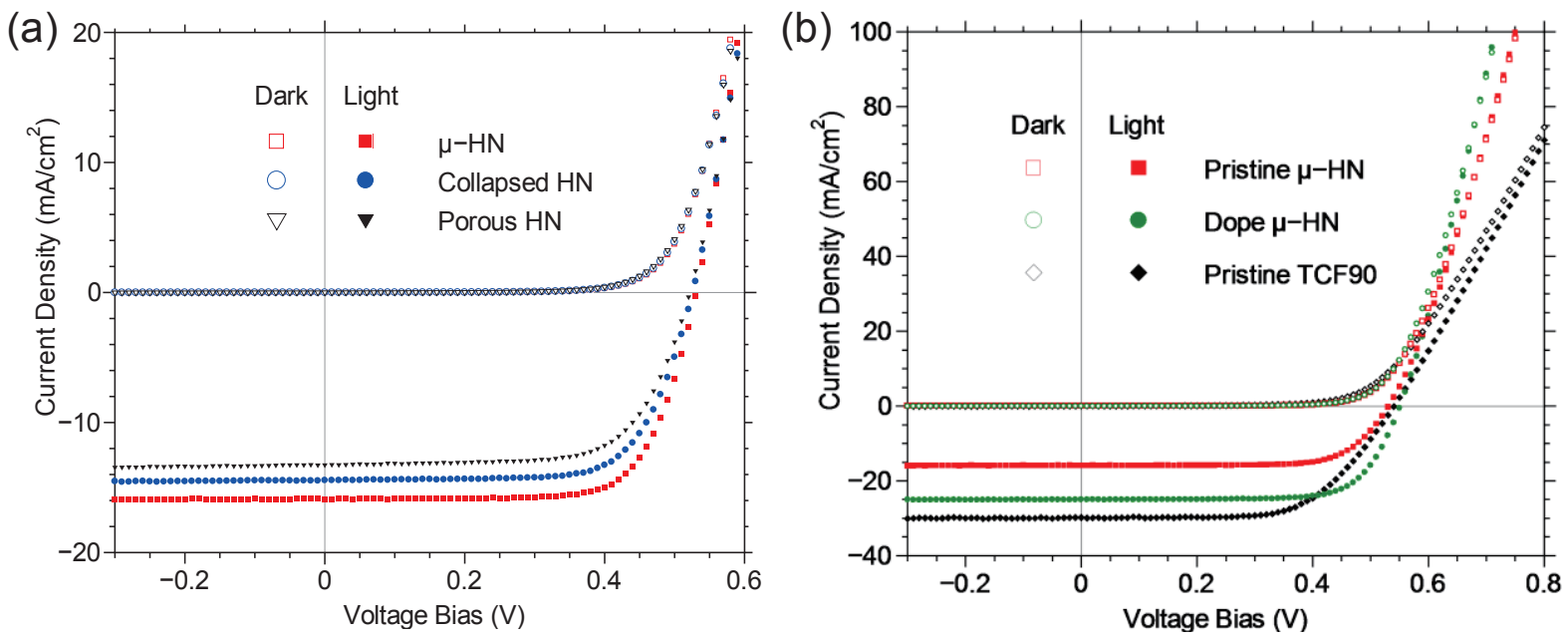

Fig. 7 (a) $J-V$ characteristics of the SWNT-Si solar cells with the $\mu$-HN, collapsed HN and porous HN SWNT films measured under dark and light conditions. (b) $J-V$ characteristics of the SWNT-Si solar cells with the pristine $\mu-\mathrm{HN}$, doped $\mu-\mathrm{HN}$ and pristine TCF90 films measured under dark and light conditions.

3.3 MODELLING The modeling and curve fitting to the experimental $J$ - $V$ curve is an insightful method for the in-depth investigation of the solar cell performance. Here, the diode equation [15] was utilized to model the operation of SWNT/Si solar cells,

$$
I=I_{s c}-I_{0} \exp \left[\frac{q\left(V+I R_{s}\right)}{n k T}\right]-\frac{V+I R_{s}}{R_{s h}}
$$

where $n$ is the ideality factor, $I_{0}$ is the dark saturation current, $k T / q$ is the thermal voltage, $I_{s c}$ is the shortcircuit current, $R_{s}$ and $R_{s h}$ are series and shunt resistance of the equivalent circuit, respectively. As shown in Fig. 8, the experimental $J-V$ curves were well-fitted by the diode equation model. Through the curving fitting of the $J-V$ characteristics, the values of $R_{s}$ and $R_{s h}$ can be extracted. For all the solar cell samples, the extracted $R_{s h}$ are over $20 \mathrm{k} \Omega$, which makes them applicable for the operation under $100 \mathrm{~mW} / \mathrm{cm}^{2}$ [13]. The extracted $R_{s}$ for the $\mu-\mathrm{HN}$, collapsed $\mathrm{HN}$ and porous $\mathrm{HN}$, as well as the nitric-acid doped $\mu$-HN are calculated as $15 \Omega, 16 \Omega, 18 \Omega$ and $11 \Omega$, respectively, while the extracted $R_{s}$ for the TCF90 sample is 33.8 $\Omega$.

The $R_{s}$ and $R_{s h}$ could be used to evaluate the quality of a solar cell and are closely related with FF. In this research, the effect of $R_{s h}$ could be ignored, owing to the very high $R_{s h}$ resulted from the $\mathrm{SiO}_{2}$ insulating layer with the thickness of $200 \mathrm{~nm}$ [12-13]. Therefore, the discussion is focused on the relationship between $R_{s}$ and FF. Besides of the five solar cell samples discussed in Fig. 7, another six SWNT-Si solar cells with illformed honeycomb networked SWNT films and randomly oriented SWNT films with 70\% (TCF70) and $80 \%$ (TCF 80 ) transparency were also compared. The relationship between the $R_{s}$ and FF of the eleven solar cell samples is given in Fig. 9. The FF values for the SWNT-Si solar cells using $\mu-\mathrm{HN}$, collapsed HN and porous $\mathrm{HN}$, as well as the nitric-acid doped $\mathrm{HN}$ were $72 \%, 70 \%, 68 \%$ and $73 \%$, respectively. The FF value 
for the SWNT/Si solar cell using the TCF90 film is 61\%. As shown in Fig. 9, the relationship between the $R_{s}$ and FF is FF $=-9.46 \ln \left(R_{s}\right)+96.534$. The FF changes exponentially with $R_{s}$. The significant improvement in terms of the FF of the hierarchical $\mu-\mathrm{HN}$ compared with that of the TCF90 is attributed to simultaneously enhanced carrier separation, collection and transport. The dense, cross-linked SWNT walls in the $\mu-\mathrm{HN}$ act as efficient conduction pathways, essentially serving as a micro-grid electrode to collect the charge carriers generated from the adjacent micro-honeycomb cells. The micro-grid configuration in the $\mu$-HN significantly shortens the minimum carrier diffusion path, resulting in more efficient photocurrent collection. In the solar cells fabricated using the collapsed $\mathrm{HN}$ and porous $\mathrm{HN}$, the micro-grid configuration still exists, which leads to their quite high FFs.

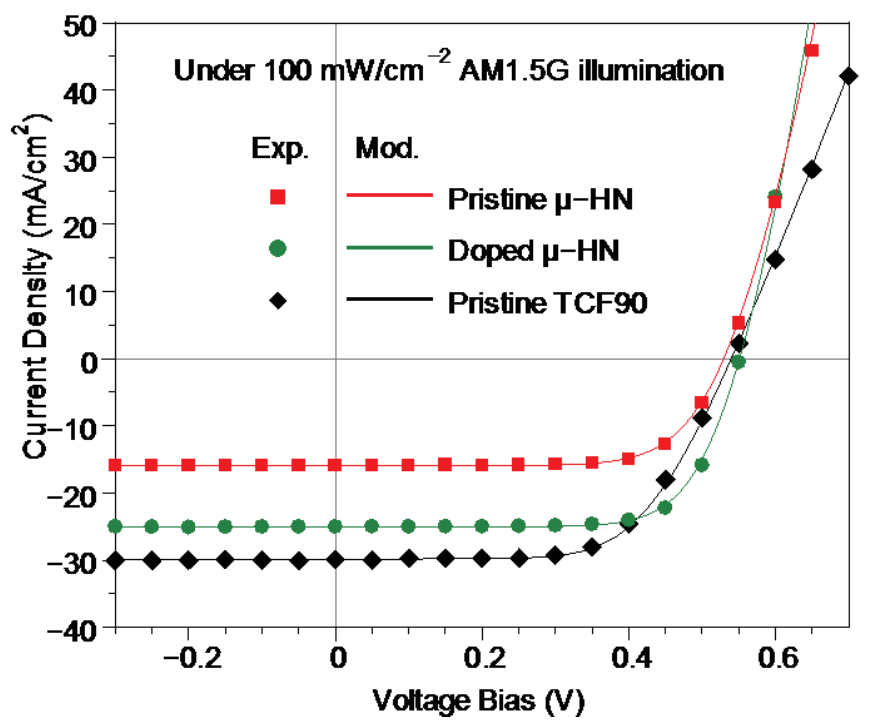

Fig. 8 Experimental and modeling results of the $J-V$ characteristics of the SWNT-Si solar cells with the pristine $\mu-\mathrm{HN}$, the doped $\mu-\mathrm{HN}$ and the pristine TCF90 films.
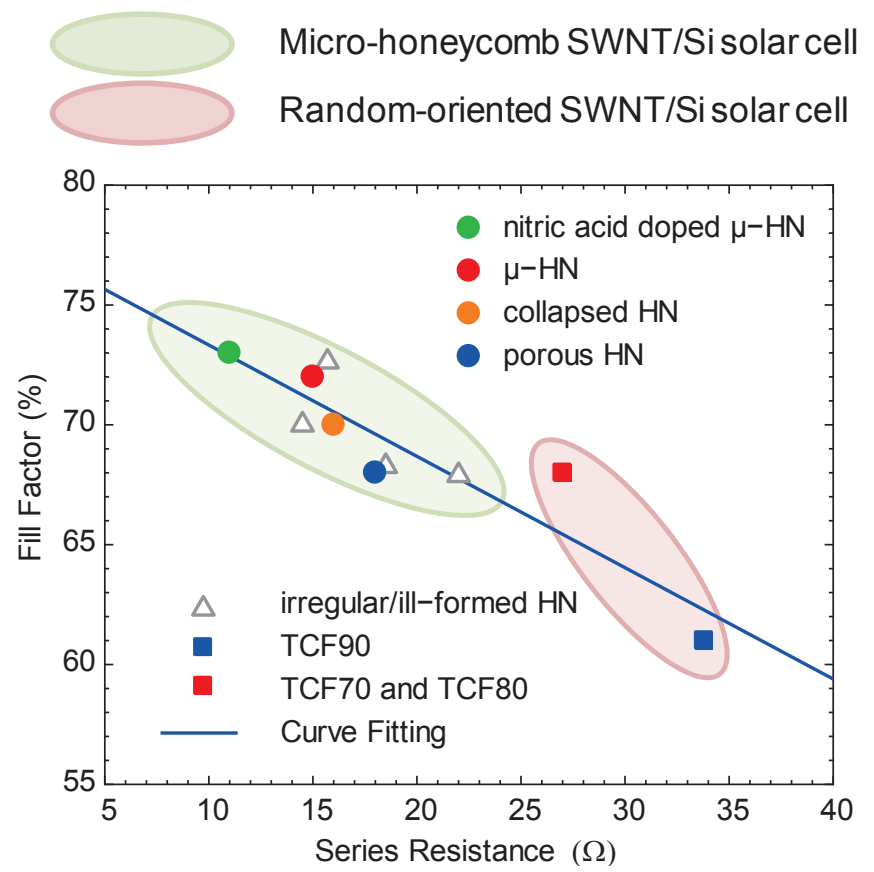

Fig. 9 The relationship between the $R_{s}$ and FF of the eleven solar cell samples: pristine and doped $\mu$-HN, collapsed HN, porous HN, four ill-formed honeycomb networked SWNT films and randomly oriented SWNT films with 70\% (TCF70), 80\% (TCF80) and 90\% (TCF90) transparency. 


\section{CONCLUSIONS}

In this study, a simple water vapor treatment to engineer the structure of VA-SWNTs into a microhoneycomb network was proposed and used for the SWNT-Si solar cells. The hierarchical $\mu$-HN consists of dense walls and a buckypaper bottom, which simultaneously increases the optical transmittance and decreases the sheet resistance. Applying $\mu-\mathrm{HN}$ to the SWNT-Si solar cell results in both high PCE and high FF. Moreover, the state-of-the-art randomly oriented SWNT film was also used for SWNT-Si soar cells, demonstrating a high PCE. The hierarchical $\mu-\mathrm{HN}$ is very promising for the applications of SWNT-Si solar cells. The full exploitation of the superior electrical, optical and chemical properties of SWNTs is very promising for the next generation photovoltaic devices.

\section{ACKNOWLEDGMENT}

Part of this work was financially supported by Grant-in-Aid for Scientific Research $(22226006,23760179$, 25630063, 25107002), EU-Japan Project "IRENA" under JST Strategic International Collaborative Research Program (SICORP) and 'Global Center for Excellence for Mechanical Systems Innovation'. K.C. thanks the UT-CSC Graduate Fellowship for financial support.

\section{NOMENCLATURE}

$\begin{array}{llllll}\text { PCE } & \text { power-conversion efficiency } & (\%) & R_{S} & \text { series resistance } & (\Omega) \\ \text { FF } & \text { fill factor } & (\%) & R_{s h} & \text { shunt resistance } & (\mathrm{k} \Omega) \\ J_{s c} & \text { short-circuit current density } & \left(\mathrm{mA} / \mathrm{cm}^{2}\right) & I_{s c} & \text { short-circuit current } & (\mathrm{mA}) \\ V_{o c} & \text { open-circuit voltage } & (\mathrm{V}) & I_{0} & \text { dark saturation current } & (\mathrm{mA})\end{array}$

\section{REFERENCES}

[1] De Volder, M. F. L., Tawfick, S. H., Baughman, R. H. and Hart, A. J., "Carbon Nanotubes: Present and Future Commercial Applications,” Science, 339(6119), pp. 535-539, (2013). Journal Paper

[2] Bindl, D. J., Wu, M. -Y., Prehn, F. C. and Arnold, M. S., "Efficiently Harvesting Excitons from Electronic Type-Controlled Semiconducting Carbon Nanotube Films," Nano Lett., 11(2), pp. 455-460, (2011). Journal Paper

[3] Dang, X. N., Yi, H., Ham, M. -H., Qi, J., Dong, S. Y., Ladewski, R., Strano, M. S., Hammond, P. T. and Belcher, A. M., "Virus-Templated Self-Assembled Single-Walled Carbon Nanotubes for Highly Efficient Electron Collection in Photovoltaic Devices," Nature Nanotech., 6(6), pp. 377-384, (2011). Journal Paper

[4] Aitola, K., Kaskela, A., Halme, J., Ruiz, V., Nasibulin, A. G., Kauppinen, E. I. and Lund, P., "Single-Walled Carbon Nanotube Thin-Film Counter Electrodes for Indium Tin Oxide-Free Plastic Dye Solar Cells," J. Electrochem. Soc., 157(12), pp. B1831B1837, 2010. Journal Paper

[5] Wei, J., Jia, Y., Shu, Q., Gu, Z., Wang, K., Zhuang, D., Zhang, G., Wang, Z., Luo, J. and Cao, A., “Double-Walled Carbon Nanotube Solar Cells," Nano Lett., 7(8), pp. 2317-2321, (2007). Journal Paper

[6] Jung, Y., Li, X., Rajan, N. K., Taylor, A. D. and Reed, M. A., "Record High Efficiency Single-Walled Carbon Nanotube/Silicon p-n Junction Solar Cells," Nano Lett., 13(1), pp. 95-99, (2012). Journal Paper

[7] Pokroy, B. Kang, S. H., Mahadevan L. and Aizenberg, L., "Self-Organization of a Mesoscale Bristle into Ordered, Hierarchical Helical Assemblies," Science, 323(5911), pp. 237-240, (2009). Journal Paper

[8] Duan, H. and Berggren, K. K., "Directed Self-Assembly at the $10 \mathrm{~nm}$ Scale by Using Capillary Force-Induced Nanocohesion," Nano Lett., 10(9), pp. 3710-3716, (2010) Journal Paper

[9] De Volder, M., and Hart, A. J., "Engineering Hierarchical Nanostructures by Elastocapillary Self-Assembly,"Angew. Chem., Int. Ed., 52(9), pp. 2412, (2013). Journal Paper

[10] Maruyama, S., Kojima, R., Miyauchi, Y., Chiashi, S. and Kohno, M., "Low-Temperature Synthesis of High-Purity SingleWalled Carbon Nanotubes from Alcohol," Chem. Phys. Lett., 360(3-4), pp. 229-234, (2002). Journal Paper

[11] Kaskela, A., Nasibulin, A. G., Timmermans, M. Y., Aitchison, B., Papadimitratos, A., Tian, Y., Zhu, Z., Jiang, H., Brown, D. P., Zakhidov, A. and Kauppinen, E. I., "Aerosol-Synthesized SWCNT Networks with Tunable Conductivity and Transparency by a Dry Transfer Technique," Nano Lett., 10(11), pp. 4349-4355, (2010). Journal Paper

[12] Cui, K., Chiba, T., Omiya, S., Thurakitseree, T., Zhao, P., Fujii, S., Kataura, H., Chiashi, S. and Maruyama, S., "SelfAssembled Micro-Honeycomb Network of Single-Walled Carbon Nanotubes for Solar Cells," J. Phys. Chem. Lett., 4(15), pp. 2571-2576, (2013). Journal Paper

[13] Cui, K., Anisimov, A., Chiba, T., Fujii, S., Kataura, H., Nasibullin, A. G., Chiashi, S., Kauppinen, E. I. and Maruyama, S., “Air-Stable High-Efficiency Solar Cells with Dry-Transferred Single-Walled Carbon Nanotube Films," J. Mater. Chem. A, doi: 10.1039/C4TA01353K, (2014). Journal Paper 
IHTC15-9485

[14] Zhou, W., Vavro, J., Nemes N. M., Fischer, J. E., Borondics, F., Kamarás, K., Tanner, D. B., Charge Transfer and Fermi Level Shift in $p$-doped Single-Walled Carbon Nanotubes. Phys. Rev. B, 71, pp. 205423-1 - 205423-7, (2005). Journal Paper

[15] Nelson, J. The Physics of Solar Cells, London: Imperial College Press, (2003). Book 